\title{
Study of the Effect of Dihydrohelenalin against Apolipoprotein E for the treatment of Alzheimer's disease: An In silico Approach
}

\author{
Khushboo Rana ${ }^{1}$, Priyanka Gautam ${ }^{1}$, Noopur Khare ${ }^{2,3}$, Abhimanyu Kumar Jha ${ }^{4,5}$ \\ ${ }^{1}$ Student, Department of Biotechnology, Faculty of Life Sciences, Institute of Applied Medicines and Research, Ghaziabad, Uttar Pradesh, \\ India, ${ }^{2}$ Research Scholar, Department of Biotechnology, Institute of Technology and Management, Meerut, Uttar Pradesh, Affiliated to \\ Dr. A.P.J. Abdul Kalam Technical University, Lucknow, Uttar Pradesh, India, ${ }^{3}$ Student, Department of Biotechnology, Shri Ramswaroop \\ Memorial University, Barabanki, Uttar Pradesh, India, ${ }^{4}$ Associate Professor, Department of Biotechnology, Faculty of Life Sciences, Institute of \\ Applied Medicines and Research, Ghaziabad, Uttar Pradesh, India, ${ }^{5}$ Associate Professor, Department of Biotechnology, Institute of Technology \\ and Management, Meerut, Uttar Pradesh, Affiliated to Dr. A.P.J. Abdul Kalam Technical University, Lucknow, Uttar Pradesh, India
}

\begin{abstract}
Alzheimer's disease (AD) is also known as neurodegenerative disease, which normally causes $60-70 \%$ of dementia. There are many genetic and environmental risk factors associated with its development. The strongest genetic risk factor occurs by apolipoprotein E (apoE). Another type of risk factor may include high blood pressure, clinical depression, and head injury. In 2015, there were 29.8 million people affected worldwide by $\mathrm{AD}$. Women get at risk more often than men. The present study was to inhibit the expression of apoE by dihydrohelenalin (DH) with the help molecular docking for the treatment of AD. The molecular docking method was performed after the screening of molecules and selecting the ligands which can inhibit and target the proteins. apoE (Protein Data Bank [PDB] ID 1GS9) protein was targeted through seven ligands compound and the best ligand was selected for further molecular docking and modeling tools. Thus, screening showed DH (with the binding affinity of $-5.3 \mathrm{kcal} / \mathrm{mol}$ ) as a ligand molecule that may inhibit apoE. DH has the highest binding properties. Thus, it may be used further used for the treatment of $\mathrm{AD}$. The $\mathrm{DH}$ may be the beneficial drug for the treatments of $\mathrm{AD}$ in future studies after in vitro and in vivo studies.
\end{abstract}

Keywords: Alzheimer's disease, Apolipoprotein E, AutoDock Vina, Ligand, Molecular docking

\section{INTRODUCTION}

Alzheimer's disease (AD) is a serious pathological disease defined through the accumulation of intracellular neurofibrillary tangles and extensive loss of neuronal and plaques by extracellular amyloid in the brain. According to clinical Phase, the sysmptoms is marked in AD by neurotransmitter loss, neuron inflammation, synaptic loss, and selective neuronal death (Holtzman et al., 2011). It was first described in 1906. Since the 1980s, AD was considered the serious cause of dementia in older adults. Therefore, in 1984, beta-amyloid protein was identified in the blood vessels of Down syndrome patients and $\mathrm{AD}$ suggested that the $21^{\text {st }}$ chromosome presents like an extra copy in people with Down syndrome. AD was classified into three types according to their genetic change in the brain such as late-onset type, early-onset type, and familial type.

Apolipoprotein is a type of protein that binds lipids to form lipoproteins and transports the lipids in lymph, blood, and cerebrospinal fluid (Samy, 2014). There are several classes of apolipoprotein such as - A, B, C, D, E, F, H, L, and M, which play specific function for their region. The major risk factor is influencing a sporadic $\mathrm{AD}$ in the form of genotype for apolipoprotein E (apoE) (Blennow et al., 2006). The humans were showing polymorphism effect in the apoE gene with three different alleles (E2, E3, and E4), based on six different phenotypes (E2/2, E2/3, E2/4, E3/3, and E4/4) (Ashford et al., 2004).

The apoE was predominantly secreted through microglia and astrocytes (Pitas et al., 1987; Uchihara et al., 1995) in the brain while neurons should produce it (Aoki et al., 2003; Xu et al., 1999). The apoE is affects lipid-binding properties and three dimensional between isoforms (Mahley et al., 1996).

Doi: $10.30954 / 2319-5169.1 .2021 .3$

Submission: 08-03-2021

Received: 09-03-2021

Acceptence: 18-05-2021

Published: 23-06-2021

${ }^{*}$ Corresponding author: Abhimanyu Kumar Jha, Department of Biotechnology, Faculty of Life Sciences, Institute of Applied Medicines and Research, Ghaziabad, Uttar Pradesh, India. E-mail: abhimanyujha630@gmail.com 
The apoE is playing a key role in the uptake and transport of cholesterol with lipoprotein receptors, including the lowdensity lipoprotein (LDL) receptors at high-affinity interaction (Wilson et al., 1991).

Molecular docking is used to screen the drug based on its structure and drug designing. The small molecules that interacted with the target protein were analyzed through docking. The molecular docking method is based on structuralbased drug designing with ligand-binding sites in a protein of three-dimensional structures (Ferreira et al., 2015). According to computational approaches, docking helps with screening the compound sets which depend on free binding energies and hypotheses the molecules can inhibit their target (Abheepsa Mishra and Satyahari Dey, 2019). The comparison of docking molecules of proteins was an alternative to the drug-like properties from the initial molecule, which can allow to calculate their recorded values. In the present study, the natural compounds from different plant sources such as oleanolic acid, dihydrohelenalin (DH), harmol, vasicinone, vasicine, chavicol, and myrcene were selected against apoE for the treatment of ADs with the help of molecular docking.

\section{MATERIALS AND METHODS}

\section{Identification of Protein by UniProt}

apoE is an associated protein with lipid particles and is mainly involved in lipoprotein-mediated lipid transport between organs through the interstitial fluids and plasma. It binds a cellular receptor including the LDL receptor and LDL receptorrelated proteins have subclasses LRP1, LRP2, and LRP8 with low-density receptor/VLDVLR. They mediate the cellular uptake and transport of apoE containing lipoprotein particles. The structure of apoE (PDB ID 1GS9) was obtained by PDB https://www.rcsb.org/(Berman, 2000).

\section{Retrieval of Ligands by PubChem}

Oleanolic acid, DH, harmol, vasicinone, vasicine, chavicol, and myrcene were used for the study of docking from the literature. Oleanolic acid is a pentacyclic triterpenoid, commonly found in olive oil and also present in different plant species. It is inhibited of the cellular inflammatory process, known to induce Phase 2 xenobiotic biotransformation enzymes. The highest amounts were found in edible parts of jujube (Ziziphus jujuba Mill.), which is commonly consumed by fruit in South Asia and China (Guo et al., 2015). It is a derivative to induced both extrinsic and intrinsic apoptosis from multiple signaling pathways.

$\mathrm{DH}$ is found in Arnica Montana. The DH esters have low response factors against ultraviolet detection. DH is responsible for the activity of anti-inflammatory properties in Arnica montana L. (Asteraceae) and their extracts have short-chain esters of sesquiterpene lactones DH. DH is inhibited collageninduced platelet aggregation, 5-hydroxytryptamine secretion, and thromboxane formation with a concentration-dependent manner at 3-300 $\mu \mathrm{m}$. While DH is reduced, the number of acid-soluble sulfhydryl groups that is present in platelets increase up to $78 \%$ than their anti-aggregatory concentrations.

Harmol was a chemical compound, which classified as $\beta$-carboline alkaloids (Abe and Kokuba, 2013). It is manufactured by harmalol, harman, harmaline, and harmine, which are related to hallucinogenic alkaloids. Harmine was first identified from the seeds of Syrian rue (Peganum harmala), found in a wild desert shrub of Central Asia, Syria, and the Middle East. Other related alkaloids are derived from the bark and stems of ayahuasca (Banisteriopsis caapi). It was found in vivo in humans from O-demethylation of harmine (Morales-Garcia et al., 2017). The $\beta$-carboline alkaloids were naturally occurring plant substances, known as a wide spectrum of psychopharmacological, neuropharmacological, and antitumor effects.

Vasicinone is a form of quinazoline alkaloid that shows bronchodilatory activity in vitro and in vivo (Amin and Mehta, 1959; Mehta et al., 1963). It was showing anti-anaphylactic action which presents with Peganum harmala (Rajani et al., 2008). Vasicinone has used the leaf extracts of Adhatoda vasica Nees, was reported that vasicinone is the major metabolite of vasicine (Amin and Mehta, 1959). They show apoptotic properties in a cell-specific manner (Qazi et al., 2014) and inhibited the PI3K/Akt/FoxO3a pathways in vivo and in vitro.

Vasicine (peganine) is found in Justicia adhatoda and it's a quinazoline alkaloid. In addition, vasicine is present in Peganum harmala (Moloudizargari et al., 2013). Their chemical formula is $\mathrm{C}_{11} \mathrm{H}_{12} \mathrm{H}_{2} \mathrm{O}$ and compared to theophylline both in vivo and in vitro (Nepali et al., 2012). They also have combination studies with their combination ratio $(1: 1)$ with bronchodilatory activity in vivo and in vitro. The alkaloids are used for respiratory stimulants (Avula et al., 2008). Vasicine is considered to have a uterine stimulant effect (Rajani et al., 2008).

Chavicol is a type of organic compound and a natural phenylpropene, which considers the benzene ring chemical structure with hydroxyl group and a propenyl group substitute. They have been found colorless liquid property with terpenes in betel oil. It is miscible with chloroform, alcohol, and ether. Their dimerization gives neolignan magnolol. It is used in odorant in perfumery and as a flavor that presents many essential oils including gardenia and anise (Lide, 2005).

Myrcene is also known as $\beta$-myrcene. Their chemical formula is $\mathrm{C} 10 \mathrm{H} 16$ with $0.794 \mathrm{~g} / \mathrm{cm}^{3}$ density. It is a type of alkene natural hydrocarbon, which may be classified due to monoterpene. Monoterpene is an isoprenoid precursor and is found in the composition of essential oil of different plants such as hops, bay, and cannabis (Behr and Johnen, 2009; Chyau et al., 1996). a-Myrcene consists of isomer 2-methyl6-methylene-1, 7-octadiene, which not present in nature (Behr and Johnen, 2009). It is described from pyrolysis $\left(400^{\circ} \mathrm{C}\right)$ of $\beta$-pinene, which is obtained by turpentine (Behr and Johnen, 2009) and directly from plants (Eggersdorfer, 2005). 
All ligand molecules were selected by the natural compound of several plants. All these ligand molecules were retrieved in 3D structure in ".sdf" format from PubChem (https://pubchem. ncbi.nlm.nih.gov/) (Graff and Mansuy, 2008) and also. All ligands structures were downloaded and can convert into a “.pdb" file through an online server (https://cactus.nci.nih.gov/ translate/) through SMILES Translator (Berman et al., 2000). The converting ".pdb" files were downloaded into ".pdb" format and run files into different tools and software's (https:// pubchem.ncbi.nlm.nih.gov/).

\section{Protein Preparation}

In protein preparation, the missing atoms in the incomplete residues are attached and the protein molecule is prepared by removing water molecules and active sites of extra ligands are also removed. The alternative conformations (disorder) are deleted along with modelling the missing loop regions in standardizing atom names (Kim et al., 2015). The docked molecule structure can be view at the time of software. This software was used for the protein molecule loaded in the graphical windows and under analyzed the view option of hierarchy. Those water molecules that were attached with ligand molecules are deleted through selecting atoms and the protein crystal structure will be saved in a.pdb format file. This. pdb format file of protein was used for docking.

\section{Preparation of Grid Parameters and Virtual Screening by PYRX}

Grid maps were used to generate and spacing by $0.375 \AA$ adjusted and cannot have ligand-binding properties. The grid dimension was adjusted to $40 \times 40 \times 40$ points. AutoDock Vina was used to interacting with docking maps and values were calculated by AutoGrid. For each and every interaction between ligand atom and receptor, the entire binding energy of the site is calculated that represented in the grid. The selected protein of interaction energy was assigned at every one point of the grid and calculated their ligand affinity.

PyRx software was used for the future virtual screening of the ligands. This software was used to demonstrate the ligands with minimum binding energy with protein target through the virtual screening. Those ligands were found their minimum binding energy with a screening of drug likeliness property analysis. The protein molecule was loaded in the PyRx window and was converted the file from the.pdb format file to.pdbqt format file and then ligands were saved in.sdf format file folder. The minimum energy of ligands was converting the.sdf file to ".pdbqt" format. The results were analyzed based on their binding affinity.

\section{Drug Likeliness Property Analysis by SwissADME}

Drug likeliness property was analyzed through an online server through SwissADME. The natural compounds were used for final molecular docking studies by screening those ligands which having drug-like properties. Canonical SMILE text ligands of notations were copied by PubChem and run on the
SwissADME online web server (Wang et al., 2016). Ligands were selected by Lipinski's rule of five. Lipinski rule of five has the following points:

1. Molecular mass is $<500 \mathrm{Da}$

2. Hydrogen bond donors only less than $5(<5)$

3. High lipophilicity can be expressed as $\log \mathrm{P}<5$

4. Hydrogen bond acceptors only allow less than $10(<10)$

5. One violation value only considered.

The ligands were based on the Lipinski rule of five and used for final docking further through AutoDock Vina.

\section{Molecular Docking Between Receptor Protein and Selected Compound by MGL Tools}

The protein target file of.pdb format was loaded on AutoDock Vina graphical windows. The protein target file of.pdb format was prepared through docking by deleting of water molecules, adding hydrogen polar atoms, and adding Kollman charges of the protein molecule and protein file was further save in ".pdbqt" format file, and compounds were converting their. pdb format file into ". pdbqt" file format. Selected the grid box was docked region. Using Autodock result in command prompt and results were analyzed (https://cactus.nci.nih.gov/ translate/.). Molecular docking was analyzed out between the target protein molecule and ligand.

\section{Structure Visualization Using PYMOL}

Structure visualization was performed through the tool PyMOL 2.4. PyMOL 2.4 is a software and freely available tool in a website server. Selected the protein molecule from the ".pdbqt" format file and was uploading in their graphical showing screen of PyMOL 2.4 tool and imported the output ".pdbqt" file in the software. The docking structure of PyMOL 2.4 was visualized through the screen and may select the option molecule was converted into "molecular surface." PyMol software was used for better visualization of protein and ligand interaction in the molecular surface. After AutoDock Vina, the output file was automatically saved in the selected folder with the name output. pdbqt file. This protein.pdbqt files with output.pdbqt files were loaded on their graphical screen of PyMol. The interaction between the protein and ligand was visualized and analyzed.

\section{RESULTS AND DISCUSSION}

The APOE crystal structure was retrieved by PDB in.pdb format, as shown in Figure 1 and Figure 2. APOE was

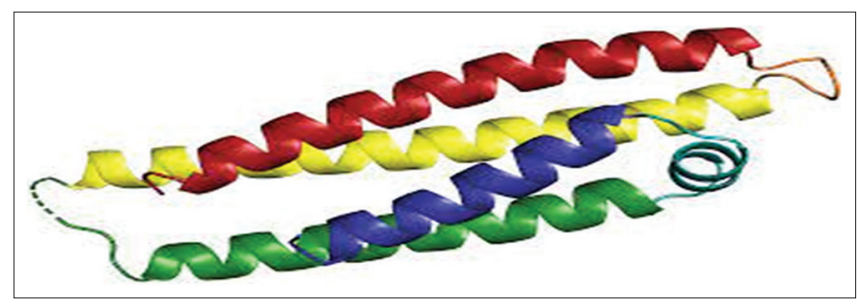

Figure 1: The structure of human apolipoprotein E [1GS9] 


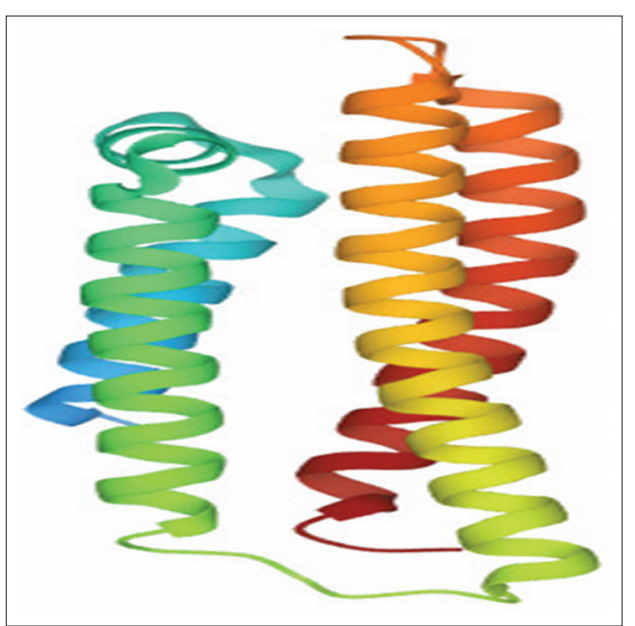

Figure 2: Biological assembly structure of protein classified by lipid-binding protein, the protein resolution value consists of $1.70 \AA$, R-value work consists of 0.218 , $\mathrm{R}$-value free consists of 0.247 , and R-value was 0.219 by following X-ray diffraction method. The protein stability was retrieved from the online database PubChem. The structures of oleanolic acid, DH, harmol, vasicinone, vasicine, chavicol, and myrcene were downloaded in 3D format structure ".sdf" file format which shown in Figure 3a-g and Figure 4. Finally, the protein structure was downloaded and converted into a ".pdb" file format.

- Protein name : $\quad$ Apolipoprotein E

- Gene : APOE

- Protein database No : 1 GS9

- Classification : Lipid-binding protein

- Organism (s) : Homo sapiens (human)

- Expression system : $\quad$ Escherichia Coli BL21

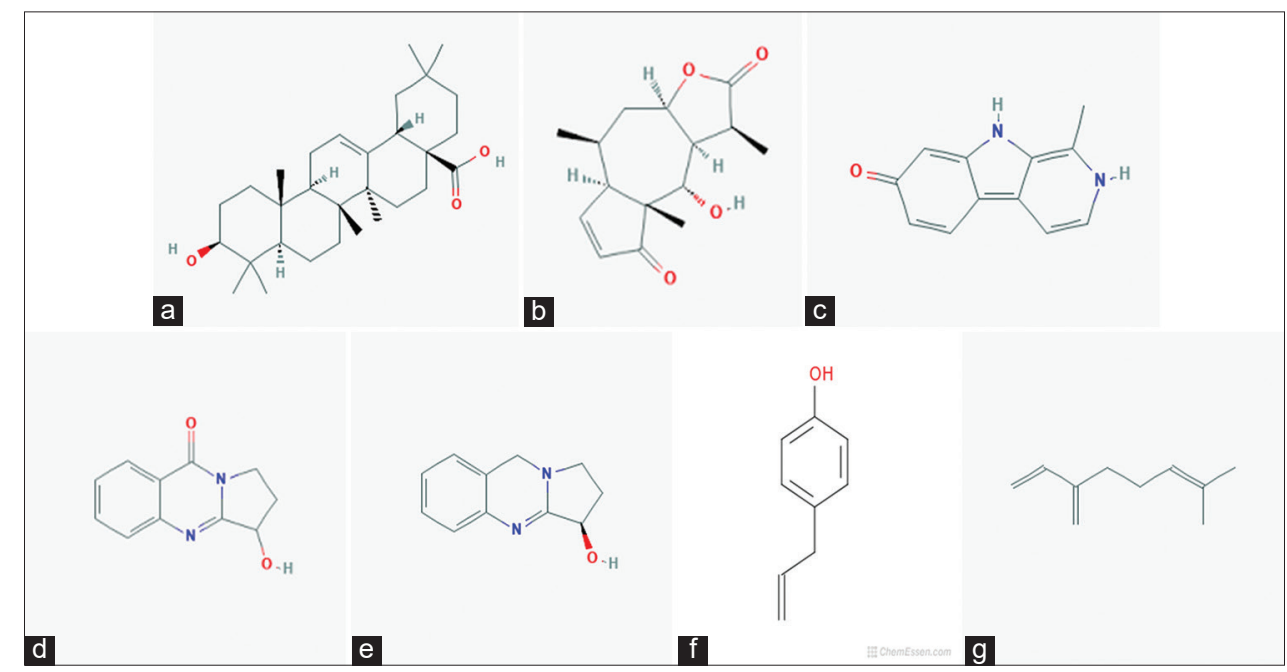

Figure 3: Structure of (a) oleanolic acid, (b) dihydrohelenalin, (c) harmol, (d) vasicinone, (e) vasicine, (f) chavicol, and (g) myrcene

Table 1: Interaction between ligands and proteins through PyRx

\begin{tabular}{|c|c|c|c|c|c|c|}
\hline Compound & Ligand & $\begin{array}{l}\text { Molecular } \\
\text { formula }\end{array}$ & Binding affinity & Mode & $\begin{array}{l}\text { RMSD lower } \\
\text { bound }\end{array}$ & $\begin{array}{c}\text { RMSD } \\
\text { upper bound }\end{array}$ \\
\hline \multirow[t]{2}{*}{ Oleanolic acid } & \multirow{2}{*}{$\begin{array}{l}\text { Apolipoprotein_E_73757787_mmff94_ } \\
\mathrm{E}=126.39\end{array}$} & \multirow[t]{2}{*}{$\mathrm{C} 30 \mathrm{H} 48 \mathrm{O} 3$} & -6.3 & 0 & 0 & 0 \\
\hline & & & -6 & 1 & 1.515 & 2.097 \\
\hline \multirow[t]{2}{*}{ Dihydrohelenalin } & \multirow{2}{*}{$\begin{array}{l}\text { Apolipoprotein_E_3032910_mmff94_ } \\
\mathrm{E}=55.82\end{array}$} & \multirow[t]{2}{*}{$\mathrm{C} 15 \mathrm{H} 20 \mathrm{O} 4$} & -5.3 & 0 & 0 & 0 \\
\hline & & & -5.2 & 1 & 22.305 & 24.29 \\
\hline \multirow[t]{2}{*}{ Harmol } & \multirow{2}{*}{$\begin{array}{l}\text { Apolipoprotein_E_68094_mmff94_ } \\
\mathrm{E}=51.18\end{array}$} & \multirow{2}{*}{$\mathrm{C} 12 \mathrm{H} 10 \mathrm{~N} 2 \mathrm{O}$} & -5.2 & 0 & 0 & 0 \\
\hline & & & -5.1 & 1 & 21.825 & 23.03 \\
\hline \multirow[t]{2}{*}{ Vasicinone } & \multirow{2}{*}{$\begin{array}{l}\text { Apolipoprotein_E_442935_mmff94_ } \\
\mathrm{E}=17.45\end{array}$} & \multirow{2}{*}{$\mathrm{C} 11 \mathrm{H} 10 \mathrm{~N} 2 \mathrm{O} 2$} & -5.1 & 0 & 0 & 0 \\
\hline & & & -5 & 1 & 21.661 & 22.711 \\
\hline \multirow[t]{2}{*}{ Vasicine } & \multirow{2}{*}{$\begin{array}{l}\text { Apolipoprotein_E_72610_mmff94_ } \\
\mathrm{E}=10.17\end{array}$} & \multirow[t]{2}{*}{$\mathrm{C} 11 \mathrm{H} 12 \mathrm{~N} 2 \mathrm{O}$} & -4.9 & 0 & 0 & 0 \\
\hline & & & -4.7 & 1 & 21.409 & 22.478 \\
\hline \multirow[t]{2}{*}{ Chavicol } & \multirow{2}{*}{$\begin{array}{l}\text { Apolipoprotein_E_68148_mmff94_ } \\
\mathrm{E}=20.34\end{array}$} & \multirow[t]{2}{*}{$\mathrm{C} 9 \mathrm{H} 10 \mathrm{O}$} & -4.3 & 0 & 0 & 0 \\
\hline & & & -4.1 & 1 & 13.694 & 14.283 \\
\hline \multirow{2}{*}{ Myrcene } & \multirow{2}{*}{$\begin{array}{l}\text { Apolipoprotein_E_31253_mmff94_ } \\
\mathrm{E}=23.90\end{array}$} & \multirow{2}{*}{$\mathrm{C} 10 \mathrm{H} 16$} & -3.8 & 0 & 0 & 0 \\
\hline & & & & 1 & 1.055 & 2.349 \\
\hline
\end{tabular}




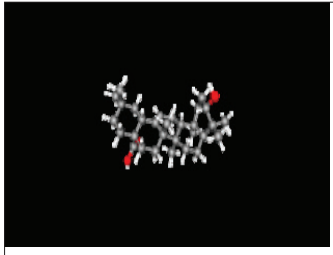

OLEANIC ACID CID- 73757787 MW- $456.70 \mathrm{~g} / \mathrm{mol}$ MF- $\mathrm{C} 30 \mathrm{H} 48 \mathrm{O} 3$

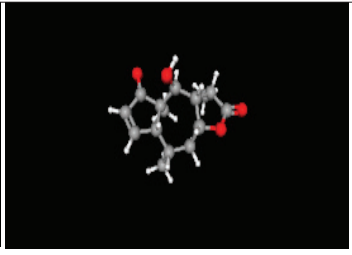

DIHYDROHELENALIN CID- 3032910 MW- $264.32 \mathrm{~g} / \mathrm{mol}$ MF- C15H20O4

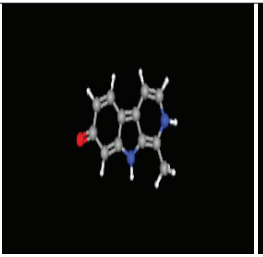

HARMOL CID- 68094 MW- $198.22 \mathrm{~g} / \mathrm{mol}$ MF- C12H10N2O

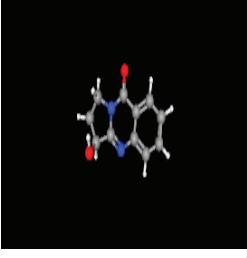

VASICINONECID442935 MW- $202.21 \mathrm{~g} / \mathrm{mol}$ MF-C11H10N2O2

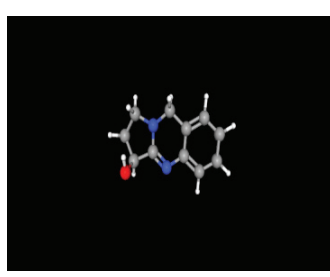

VASICINE

CID- 72610

MW- $188.23 \mathrm{~g} / \mathrm{mol}$ MF-C11H12N2O

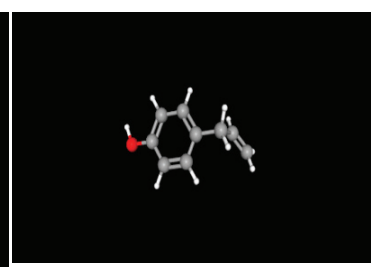

CHAVICOL CID- 68148 MW- $134.18 \mathrm{~g} / \mathrm{mol}$ MF- C9H10O

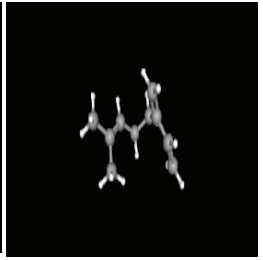

MYRCENE

CID- 31253

MW- $136.23 \mathrm{~g} / \mathrm{mol}$ MF- C10H16

Figure 4: Three-dimensional crystalline structure of ligands with their CID, MW, and MF
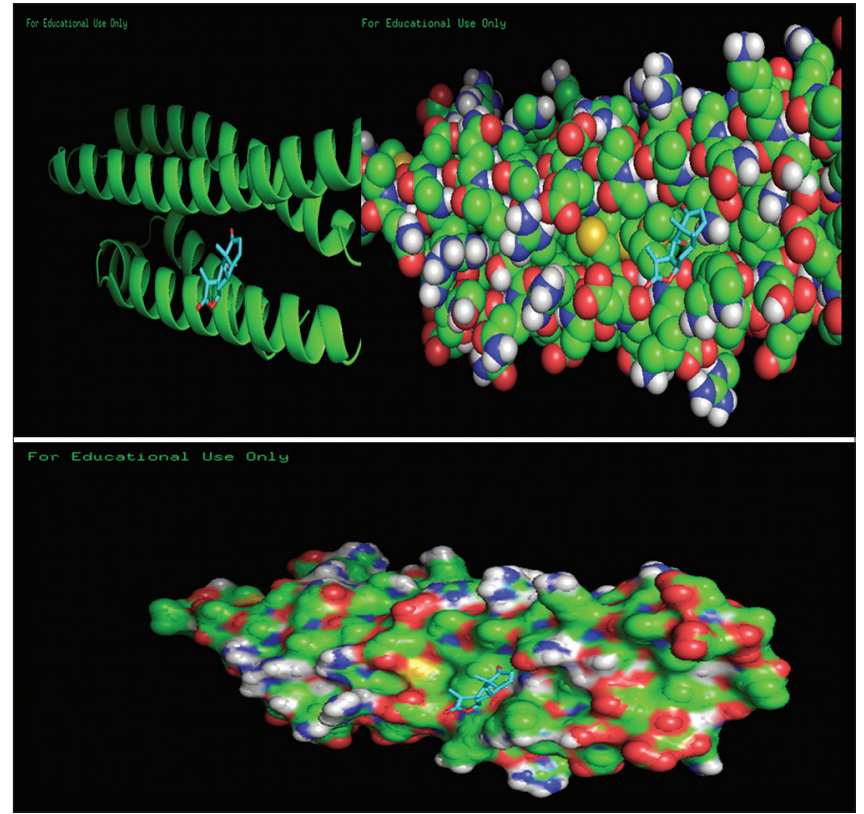

Figure 5: Interaction of apolipoprotein E protein within dihydrohelenalin ligand through PyMOL visualizer

- Mutation : Yes

- Sequence length : 165

All these seven oleanolic acid, DH, harmol, vasicinone, vasicine, chavicol, and myrcene ligands were used for virtual screening by PyRx software and result, as shown in Table 1. The DH retrieved the binding affinity $-5.3 \mathrm{Kcal} / \mathrm{mol}$, and having $\mathrm{C}_{15} \mathrm{H}_{2} \mathrm{OO}_{4}$ molecular formula with root mean square deviation (RMSD) lower bound value was 0 and upper bound value was 0 in Mode 0 and if we considered the value in mode 1 , then binding affinity was retrieved $-5.2 \mathrm{Kcal} / \mathrm{mol}$
Table 2: Binding energies of different compounds with CID number

\begin{tabular}{llcc}
\hline S. No. & Compound & CID & Binding energy \\
\hline 1. & Oleanolic acid & 73757787 & -6.3 \\
2. & Dihydrohelenalin & 3032910 & -5.3 \\
3. & Harmol & 68094 & -5.2 \\
4. & Vasicinone & 442935 & -5.1 \\
5. & Vasicine & 72610 & -4.9 \\
6. & Chavicol & 68148 & -3.8 \\
\hline
\end{tabular}

with RMSD lower bound value was 22.305 and having upper bound value was 24.29 in above table.

In the PyRx results, among all the ligand molecules, DH and oleanolic acid showed minimum binding energy. The screening molecules of oleanolic acid, DH, harmol, vasicinone, vasicine, chavicol, and myrcene were analyzed for drug likeliness property analysis from SwissADME. The screening of all seven ligands was analyzed through the online web server SwissADME. Further, these seven ligands were considered through their qualifying Lipinski's rule of five screened. Oleanolic acid has found minimum binding energy with its specific protein molecule but they have one violation. On the other hand, DH also having minimum binding energy with ligands and protein molecule but they have 0 violation; it was good to qualify the rule of qualifying Lipinski's rule of five.

The DH ligand was screened by docking of protein target through AutoDock Vina. AutoDock Vina was software; ligand was retrieved minimum binding energy. DH was retrieved best binding ligand affinity against protein target by AutoDock Vina, as shown in Table 4. 
Table 3: Result analyzed by drug likeliness property analysis

\begin{tabular}{lcccccc}
\hline Ligands & $\begin{array}{c}\text { Binding } \\
\text { affinity }\end{array}$ & Molecular weight & $\begin{array}{c}\text { No. of H-bond } \\
\text { acceptors < 10 }\end{array}$ & $\begin{array}{c}\text { No. of H-bond } \\
\text { donors }<\mathbf{5}\end{array}$ & $\begin{array}{c}\text { Log Po/w } \\
{[\text { MLOGP] }<\mathbf{5}}\end{array}$ & Violation \\
\hline Oleanolic acid & -6.4 & $456.7 \mathrm{~g} / \mathrm{mol}$ & 3 & 2 & 5.82 & Yes; 1 violation: MLOGP>4.15 \\
Dihydrohelenalin & -5.3 & $264.32 \mathrm{~g} / \mathrm{mol}$ & 4 & 1 & 1.62 & Yes; 0 violation \\
Harmol & -5.2 & $198.22 \mathrm{~g} / \mathrm{mol}$ & 1 & 2 & 0.95 & Yes; 0 violation \\
Vasicinone & -5.1 & $202.21 \mathrm{~g} / \mathrm{mol}$ & 3 & 1 & 0.78 & Yes; 0 violation \\
Vasicine & -4.9 & $188.23 \mathrm{~g} / \mathrm{mol}$ & 2 & 1 & 1.57 & Yes; 0 violation \\
\hline
\end{tabular}

Table 4: Comparing result through PyRx and SwissADME

\begin{tabular}{|c|c|c|c|c|c|c|c|c|c|}
\hline Ligand & $\begin{array}{l}\text { Binding } \\
\text { affinity }\end{array}$ & Mode & RMSD L.B & RMSD U.B & MW & $\begin{array}{c}\text { No. of } \\
\text { H-bond } \\
\text { acceptor }\end{array}$ & $\begin{array}{l}\text { No. of H-bond } \\
\text { donors }\end{array}$ & $\begin{array}{l}\log \text { Po/w } \\
\text { [MLOGP] }\end{array}$ & Violation \\
\hline Oleanolic acid & -6.0 & 1 & 1.515 & 2.097 & $456.7 \mathrm{~g} / \mathrm{mol}$ & 3 & 2 & 5.82 & $\begin{array}{l}\text { Yes; } 1 \text { violation: } \\
\text { MLOGP> }>4.15\end{array}$ \\
\hline Dihydrohelenalin & -5.2 & 1 & 22.305 & 24.29 & $264.32 \mathrm{~g} / \mathrm{mol}$ & 4 & 1 & 1.62 & Yes; 0 violation \\
\hline Harmol & -5.1 & 1 & 21.825 & 23.03 & $198.22 \mathrm{~g} / \mathrm{mol}$ & 1 & 2 & 0.95 & Yes; 0 violation \\
\hline Vasicinone & -5.0 & 1 & 21.661 & 22.711 & $202.21 \mathrm{~g} / \mathrm{mol}$ & 3 & 1 & 0.78 & Yes; 0 violation \\
\hline Vasicine & -4.7 & 1 & 21.409 & 22.478 & $188.23 \mathrm{~g} / \mathrm{mol}$ & 2 & 1 & 1.57 & Yes; 0 violation \\
\hline Chavicol & -4.1 & 1 & 13.694 & 14.283 & $134.18 \mathrm{~g} / \mathrm{mol}$ & 1 & 1 & 2.37 & Yes; 0 violation \\
\hline Myrcene & -3.8 & 1 & 1.055 & 2.349 & $136.23 \mathrm{~g} / \mathrm{mol}$ & 0 & 0 & 3.56 & Yes; 0 violation \\
\hline
\end{tabular}

Table 5: AutoDock Vina result

\begin{tabular}{lccc}
\hline Mode & Affinity $(\mathrm{Kcal} / \mathbf{m o l})$ & \multicolumn{2}{c}{ Dist. from best mode } \\
\cline { 3 - 4 } & & $\begin{array}{c}\text { RMSD } \\
\text { lower bound }\end{array}$ & $\begin{array}{c}\text { RMSD upper } \\
\text { bound }\end{array}$ \\
\hline 1 & -6.3 & 0.000 & 0.000 \\
2 & -6.0 & 28.013 & 29.705 \\
3 & -5.8 & 28.43 & 30.38 \\
4 & -5.5 & 21.489 & 23.615 \\
5 & -5.4 & 1.850 & 2.879 \\
6 & -5.4 & 22.626 & 24.877 \\
7 & -5.3 & 1.720 & 4.948 \\
8 & -5.3 & 18.780 & 20.797 \\
9 & -5.2 & 1.643 & 5.252 \\
\hline
\end{tabular}

DH was having a very strong type of binding affinity and targets their specific region. The interaction between target proteins through ligand based on visualized PyMOL software in Figure 5. DH was an inhibitor that forms a drug for controlling AD by in silico study, Thus, this drug is very effective for the treatment of AD in future prospects.

\section{CONCLUSION}

The crystalline structure of protein APOE was docked by molecular docking software. Docking studies of $\mathrm{DH}$ were showing their strong affinity toward AD protein target. According to an in silico study, DH may act as an inhibitor which forms a drug for controlling of $\mathrm{AD}$ and also can be used for the treatment of AD.

\section{CONFLICTS OF INTEREST STATEMENT}

The authors declare that there are no conflicts of interest.

\section{ACKNOWLEDGMENTS}

The authors acknowledge the help provided by the Department of Biotechnology, Faculty of Life Sciences, Institute of Applied Medicines and Research, Ghaziabad, Uttar Pradesh, India.

\section{REFERENCES}

Abe, A. and Kokuba, H. 2013. Harmol induces autophagy and subsequent apoptosis in U251MG human glioma cells through the downregulation of survivin. Oncol. Rep., 29, 1333-1342.

Abheepsa Mishra, and SatyahariDey; Molecular Docking Studies of a Cyclic Octapeptide-Cyclosaplin from Sandalwood, Biomolecules, 2019, 9(740).

Amin, A.H. and Mehta, D.R. 1959. A bronchodilator alkaloid (vasicinone) from Adhatoda vasica Nees. Nature, 184, 13171317.

Aoki, K., Uchihara, T., Sanjo, N., Nakamura, A., Ikeda, K., Tsuchiya, K. and Wakayama, Y. 2003. Increased expression of neuronal apolipoprotein $\mathrm{E}$ in human brain with cerebral infarction. Stroke, 34, 875-880.

Ashford, J.W. 2004. APOE genotype effects on Alzheimer's disease onset and epidemiology. J. Mol. Neurosci., 23, 157-165.

Avula, B., Begum, S., Ahmed, S., Choudhary, M.I. and Khan, I.A. 2008. Quantitative determination of vasicine and vasicinone in Adhatoda vasica by high performance capillary electrophoresis. Pharmazie, 63, 20-22.

Behr, A. and Johnen, L. 2009. Myrcene as a natural base chemical in 
sustainable chemistry: A critical review. Chem. Sustain. Chem., 2, 1072-1095.

Berman, H.M. 2000. The Protein Data Bank. Nucleic Acids Res., 28, 235-242.

Berman, H.M., Henrick, K. and Nakamura, H. 2000. Announcing the worldwide protein data bank. Nat. Struct. Biol., 10, 980.

Blennow, K., De Leon, M.J. and Zetterberg, H. 2006. Alzheimer's disease. Lancet, 368, 387-403.

Chyau, C.C., Mau, J.L. and Wu, C.M. 1996. Characteristics of the steam-distilled oil and carbon dioxide extract of Zanthoxylum simulans fruits. J. Agric. Food Chem., 44, 1096-1099.

Eggersdorfer, M. 2005. Terpenes Ullmann's Encyclopedia of Industrial Chemistry. Wiley-VCH, Weinheim.

Ferreira, L., dos Santos, R., Oliva, G. and Andricopulo, A. 2015. Molecular docking and structure-based drug design strategies. Molecules, 20, 13384-13421.

Graff, J. and Mansuy, I.M. 2008. Epigenetic codes in cognition and behaviour. Behav. Brain Res., 192, 70-87.

Guo, S., Duan, J., Qian, D., Tang, Y., Wu, D., Su, S., Wang, H. and Zhao, Y. 2015. Content variations of triterpenic acid, nucleoside, nucleobase, and sugar in jujube (Ziziphusjujuba) fruit during ripening. Food Chem., 167, 468-474.

Holtzman, D.M., Morris, J.C. and Goate, A.M. 2011. Alzheimer's disease: The challenge of the second century. Sci. Transl. Med., $3,77-71$.

Kim, S., Thiessen, P.A., Bolton, E.E., Chen, J., Fu, G., Gindulyte, A. and Bryant, S.H. 2015. PubChem substance and compound databases. Nucleic Acids Res., 44, D1202-D1213.

Lide, D.R., editor. 2005. CRC Handbook of Chemistry and Physics. $86^{\text {th }}$ ed. CRC Press, Boca Raton, FL.

Mahley, R.W., Nathan, B.P. and Pitas, R.E. 1996. Apolipoprotein E. structure, function, and possible roles in Alzheimer's disease. Ann. N. Y. Acad. Sci., 777: 139-145.

Mehta, D.R., Naravane, J.S. and Desai, R.M. 1963. Vasicinone. A bronchodilator principle from Adhatoda vasica Nees (N. O. Acanthaceae). J. Org. Chem., 28, 445-448.

Moloudizargari, M., Mikaili, P., Aghajanshakeri, S., Asghari, M.H. and Shayegh, J. 2013. Pharmacological and therapeutic effects of Peganum harmala and its main alkaloids. Pharmacogn. Rev., 7, 199-212.

Morales-Garcia, J.A., de la Fuenta Revenga, M., Alonso-Gil, S., Rodriguez-Franco, M.I., Feiding, A., Perez-Castillo, A. and
Riba, J. 2017. The alkaloids of Banisteriopsis caapi, the plant source of the Amazonian hallucinogen Ayahuasca, stimulate adult neurogenesis in vitro. Sci. Rep., 7, 5309.

Nepali, K., Sharma, S., Ojha, R. and Dhar, K.L. 2012. Vasicine and structurally related quinazolines. Med. Chem. Res., 22, 1-15.

Pitas, R.E., Boyles, J.K., Lee, S.H., Foss, D. and Mahley, R.W. 1987. Astrocytes synthesize apolipoprotein E and metabolize apolipoprotein E-containing lipoproteins. Biochim. Biophys. Acta, 917, 148-161.

Qazi, A.K., Hussain, A., Aga, M.A., Ali, S., Taneja, S.C., Sharma, P.R., Saxena, A.K., Mondhe, D.M. and Hamid, A. 2014. Cell specific apoptosis by RLX is mediated by NFKB in human colon carcinoma HCT-116 cells. BMC Cell Biol., 15, 36.

Rajani, M., Soni, S., Anandjiwala, S. and Patel, G. 2008. Validation of different methods of preparation of Adhatoda vasica leaf juice by quantification of total alkaloids and vasicine. Indian $J$. Pharm. Sci., 70, 36-42.

Samy, I.R. 2014. Recent advances in physiological lipoprotein metabolism. Clin. Chem. Lab. Med., 52, 1695-1727.

Uchihara, T., Duyckaerts, C., He, Y., Kobayashi, K., Seilhean, D., Amouyel, P. and Hauw, J.J. 1995. ApoEimmunoreactivity and microglial cells in Alzheimer's disease brain. Neurosci. Lett., 195, 5-8.

Wang, W., Xia, M., Chen, J., Deng, F., Yuan, R., Zhang, X. and Shen, F. 2016. Data set for phylogenetic tree and RAMPAGE Ramachandran plot analysis of SODs in Gossypium raimondii and G. arboreum. Data Brief, 9, 345-348.

Wilson, C., Wardell, M.R., Weisgraber, K.H., Mahley, R.W. and Agard, D.A. 1991. Three-dimensional structure of the LDL receptor-binding domain of human apolipoprotein E. Science, 252, 1817-1822.

Xu, P.T., Gilbert, J.R., Qiu, H.L., Ervin, J., Rothrock-Christian, T.R., Hulette, C. and Schmechel, D.E. 1999. Specific regional transcription of apolipoprotein $\mathrm{E}$ in human brain neurons. $\mathrm{Am}$. J. Pathol., 154, 601-611.

How to cite this article: Rana, K., Gautam, P., Khare, N., Jha, A.K. 2021. Study of the Effect of Dihydrohelenalin against Apolipoprotein E for the treatment of Alzheimer's disease: An In silico Approach. Int. J. Bioinform. Biol. Sci. 9(1), 16-22. 